\title{
Development of cabozantinib for the treatment of prostate cancer
}

This article was published in the following Dove Press journal:

Core Evidence

23 April 2014

Number of times this article has been viewed

\section{Ulka N Vaishampayan}

Department of Oncology, Wayne State University/Karmanos Cancer Institute, Detroit, MI, USA
Correspondence: Ulka N Vaishampayan Wayne State University, 4100 John R,

Detroit MI 4820I, USA

Tel + I 3135768715

Fax + I 3135768487

Email vaishamu@karmanos.org
Abstract: Cabozantinib (XL184) is a multitargeted receptor tyrosine kinase with predominantly $M E T$ and vascular endothelial growth factor inhibition properties. It is currently approved by the US Food and Drug Administration for the treatment of progressive metastatic medullary thyroid cancer. The agent has a convenient once-daily oral dosing schedule and has demonstrated encouraging activity in metastatic castrate-resistant prostate cancer (CRPC). A Phase I/II trial demonstrated responses in soft tissue, visceral disease, and bone metastases in CRPC. An objective response rate of $5 \%$, a stable disease rate of $75 \%$, and a median progression-free survival of 6 months was observed. As compared with the $140 \mathrm{mg}$ daily dose used in thyroid cancer, a lower dose of $60 \mathrm{mg}$ daily is currently being utilized in prostate cancer studies due to the fact that toxicity could be reduced without compromising efficacy. Randomized trials are ongoing in comparison with prednisone or with mitoxantrone and prednisone in pretreated metastatic CRPC. Cabozantinib has demonstrated a unique mechanism of action and preliminary efficacy in the crowded therapeutic field of prostate cancer. Since multiple therapies have recently demonstrated overall survival benefit in metastatic CRPC, cabozantinib will likely face some challenges in clinical application. At present, in this rapidly evolving field, it is unclear what proportion of patients with prostate cancer will be eligible to receive this therapy. The cost of cabozantinib is likely to be another deterrent, especially if it remains more expensive than other oral therapies, such as abiraterone and enzalutamide. Defining the role of MET overexpression and RET mutations as biomarkers in prostate cancer may help to guide patient selection, and enrich and enhance the future applications of this targeted novel agent.

Keywords: XL184, castrate-resistant, vascular endothelial growth factor, MET, tyrosine kinase, metastasis

\section{Core evidence clinical impact summary for cabozantinib}

\begin{tabular}{|c|c|c|}
\hline Perspective & Favorable evidence & Problems/concerns \\
\hline \multirow{13}{*}{$\begin{array}{l}\text { Physician/ } \\
\text { disease } \\
\text { oriented }\end{array}$} & Preclinical rationale & Comparison trials with control group are still in \\
\hline & Clinical efficacy & progress \\
\hline & Distinct mechanism & Durability of remissions \\
\hline & of action & Difficult to carve a niche in a crowded therapeutics \\
\hline & Preclinical rationale & field \\
\hline & Clinical efficacy & No associated identifiable biomarker to guide therapy \\
\hline & Nonoverlapping toxicities & A limited proportion of patients will receive seventh \\
\hline & with other agents, & line therapy (six systemic agents currently approved \\
\hline & especially chemotherapy & by the US FDA) \\
\hline & Combination trials are & Response assessment is challenging as PSA can be \\
\hline & planned/ongoing & discordant with response and bone scan response \\
\hline & Possibility of complete & quantification is not yet validated for this agent \\
\hline & response on bone scan & \\
\hline
\end{tabular}

(Continued) 


\begin{tabular}{|c|c|c|}
\hline $\begin{array}{l}\text { (Continued) } \\
\text { Perspective }\end{array}$ & Favorable evidence & Problems/concerns \\
\hline $\begin{array}{l}\text { Patient- } \\
\text { oriented }\end{array}$ & $\begin{array}{l}\text { Convenient oral } \\
\text { once-daily dosing } \\
\text { Pain control } \\
\text { Off narcotic pain } \\
\text { medications } \\
\text { Possibility of CR }\end{array}$ & $\begin{array}{l}\text { No proven survival benefit as yet } \\
\text { Toxicities such as hypertension, fatigue are not trivial } \\
\text { Cost }\end{array}$ \\
\hline $\begin{array}{l}\text { Economic } \\
\text { impact/costs } \\
\text { of agents }\end{array}$ & $\begin{array}{l}\text { Midrange cost as } \\
\text { compared with other } \\
\text { agents with OS benefit } \\
\text { Cabozantinib costs } \\
\$ 9,900 \text { per month } \\
\text { (current known cost, } \\
\text { may be different for dose } \\
\text { used in prostate cancer if } \\
\text { approved by the US FDA) } \\
\text { Sipuleucel T costs } \\
\$ 31,000 \text { per injection, } \\
\text { course of three injections } \\
\text { Alpharadin costs } \$ 11,500 \\
\text { per injection, course of } \\
\text { six injections }\end{array}$ & $\begin{array}{l}\text { Can we justify the cost especially if it is used just for } \\
\text { pain control? } \\
\text { Mitoxantrone which has palliative benefit alone } \\
\text { without OS benefit is now generic and costs } \\
\text { about } \$ 42 \\
\text { Very hard to cover out of pocket expenses } \\
\text { Cost is high as compared with following } \\
\text { agents showing OS benefit: } \\
\text { Enzalutamide, } \$ 7,450 \\
\text { Cabazitaxel, } \$ 5,598.29 \\
\text { Abiraterone, } \$ 5,000 \\
\text { Docetaxel, } \$ 2,483\end{array}$ \\
\hline
\end{tabular}

\section{Introduction}

The world of prostate cancer therapeutics has undergone a major overhaul in the last 5 years. Numerous agents with multiple, nonoverlapping mechanisms of action have achieved US Food and Drug Administration (FDA) approval for the indication of metastatic castrate-resistant prostate cancer (CRPC). ${ }^{1-5}$ Cabozantinib (Cometriq ${ }^{\circledR}$; Exelexis Inc., South San Francisco, CA, USA) faces the challenge of entering a crowded marketplace. It does, however, demonstrate the unique phenomenon of complete response or normalization of bone scans in metastatic prostate cancer. ${ }^{6}$ This type of transformation on bone scan has not been observed, even with androgen deprivation therapy, which to this day remains the most effective front-line systemic therapy for prostate cancer. Despite recent advances, there is an ongoing clinical need to develop better therapies for advanced prostate cancer, to improve the chance of achieving long-term remission. Higher levels of MET expression are noted in prostate cancer cells, as compared with benign prostatic hyperplasia, which correlates directly with a higher grade of cancer. ${ }^{7}$ The resistance pathways in metastatic disease consist of hypoxia, leading to overexpression of $M E T$ and an increase in vascular endothelial growth factor (VEGF) levels, resulting in increasing angiogenesis and invasion. ${ }^{7}$ The clinical efficacy of cabozantinib is well established in medullary thyroid cancer by level I evidence from a well conducted, randomized, placebo-controlled, double-blind clinical trial. ${ }^{8}$
Cabozantinib has dual VEGF and Met inhibition properties and fits the current need for a distinctive novel target in prostate cancer therapy. ${ }^{7}$ Although a preliminary anticancer effect was noted in metastatic CRPC, the clinical efficacy of cabozantinib cannot be accepted until the results of randomized trials are available. The potential clinical and economic impact if cabozantinib is approved by the US FDA for use in metastatic CRPC is summarized above.

\section{Mechanism of action Importance of MET in cancer}

In medullary thyroid cancer, the pathways of MET, RET, and VEGF appear to be pathophysiological for disease progression and proliferation. MET is activated by hepatocyte growth factor and both are broadly expressed in adult tissues and implicated in postnatal physiological and pathophysiological processes.

Upregulated hepatocyte growth factor and Met expression is observed in several injured tissues. After liver, kidney, or heart injury, plasma levels of hepatocyte growth factor rise, and increased expression is observed in other organs too, indicating this might be a general physiological response to tissue damage. It is also noted that release of cytokines such as interleukin- 1 and interleukin- 6 activate transcription of hepatocyte growth factor. ${ }^{9}$ Germline mutation in the tyrosine kinase domain of the c-MET proto-oncogene on chromosome $7 \mathrm{q} 31$ results in derangement of processes like angiogenesis, 
Table I Clinical activity of cabozantinib in prostate cancer

\begin{tabular}{|c|c|c|c|c|}
\hline Author/ref & Study design & Response rate & PFS & $\begin{array}{l}\text { Predominant toxicities } \\
\text { (Grade } 3 \text { or } 4 \text { ) }\end{array}$ \\
\hline Smith et al ${ }^{6}$ & $\begin{array}{l}\text { Phase II randomized } \\
\text { discontinuation trial } \\
\text { Starting dose } 100 \mathrm{mg} \text { daily }\end{array}$ & $\begin{array}{l}\text { ORR-7.6\% } \\
\text { SD-75\% } \\
\text { Bone scan CR-12\% } \\
\text { Bone pain relief-67\% }\end{array}$ & $\begin{array}{l}\text { Median } 23.9 \text { weeks with } \\
\text { cabozantinib vs } 5.9 \text { weeks } \\
\text { with placebo }\end{array}$ & $\begin{array}{l}\text { Fatigue } 16 \% \\
\text { Hypertension } 12 \% \\
\text { Hand foot syndrome } 8 \%\end{array}$ \\
\hline Lee et $\mathrm{al}^{30}$ & $\begin{array}{l}\text { Dose ranging study: } \\
\text { adaptive scheme } \\
\text { Doses of } 40 \text { and } 20 \mathrm{mg} \text { daily. } \\
\text { Dose escalation to } 60 \mathrm{mg} \\
\text { was planned is necessary }\end{array}$ & $\begin{array}{l}40 \mathrm{mg} \text { daily dose: } \\
\text { I5/24 PR } \\
\text { I/II CR } \\
\text { 8/24 SD } \\
\text { 0/24 PD } \\
20 \mathrm{mg} \text { daily dose: } \\
\text { I/I0 PR } \\
\text { 0/I0 CR } \\
5 / 10 \mathrm{SD} \\
\text { 5/I0 PD }\end{array}$ & $\begin{array}{l}\text { Overall bone scan } \\
\text { response: } 68 \% \\
\text { Pain response: } 67 \% \\
\text { Median treatment duration } \\
25.9 \text { weeks on the } 40 \mathrm{mg} \\
\text { dose cohort }\end{array}$ & $\begin{array}{l}\text { Anorexia, fatigue, weight loss } \\
\text { were the most likely Grade I } \\
\text { or } 2 \text { adverse events } \\
\text { I Grade } 3 \text { thromboembolism } \\
\text { noted. }\end{array}$ \\
\hline
\end{tabular}

Abbreviations: vs, versus; ref, reference; SD, stable disease; CR, complete response; PR, partial response; PD, progressive disease; ORR, overall response rate; PFS, progression free survival.

cell motility, proliferation, and morphogenic differentiation. ${ }^{10-12}$ This ultimately contributes to carcinogenesis and progression of malignancy. The MET tyrosine kinase receptor for hepatocyte growth factor has been implicated as a mediator in many important aspects of tumor pathobiology, including tumor survival, growth, angiogenesis, invasion, and dissemination, ${ }^{9,10}$ and several MET tyrosine kinase receptors have been reported to show activity in cell lines and animal models. Met and VEGFR2 play synergistic roles in promoting tumor angiogenesis and subsequent dissemination. ${ }^{13-15}$ In summary, MET protects cancer cells against apoptosis, increases their invasive ability, motility, and epithelialmesenchymal transition, and promotes resistance to VEGF inhibitor therapy.

Dysregulation of the MET/VEGF axis has been reported in human malignancies, and this effect is likely to be seminal in a tumor such as prostate cancer, for which the most common site of metastasis is bone. VEGF results in phosphorylation of $M E T$ and activates the hepatocyte growth factor/MET pathway. VEGF alone without MET inhibition promotes rapid progression of tumors, as demonstrated in animal models. ${ }^{10,11}$ Cabozantinib is a novel, orally bioavailable inhibitor of multiple receptor tyrosine kinases with growth-promoting and angiogenic properties. ${ }^{7}$ Data from pharmacodynamic experiments show that cabozantinib inhibits MET and VEGFR2 (vascular endothelial growth factor receptor 2) in vivo. Cabozantinib also demonstrates an inhibitory effect against KIT and RET, thus making it clinically effective against medullary thyroid cancer. ${ }^{8}$ Oral administration of cabozantinib resulted in blockade of $M E T$ phosphorylation in human lung tumor xenografts grown in nude mice, blockade of MET phosphorylation in the mouse liver, and blockade of VEGFR2 phosphorylation in mouse lung tissue. Treatment with cabozantinib results in antiangiogenic effects in xenograft tumors, with disruption of the vasculature starting within 24 hours of administration and proapoptotic effects. These effects translate into significant inhibition of tumor growth or tumor regression after treatment with cabozantinib in multiple tumor models, including medullary thyroid cancer, prostate cancer, breast cancer, carcinoma of the lung, and glioblastoma. ${ }^{7}$

Treatment with cabozantinib for 3 weeks inhibited the development of liver metastasis in the RIP-Tag2 model. ${ }^{16,17}$ This was in contrast with the increased number of metastases noted in the same model with anti-VEGF treatment alone. The number of liver metastases observed was five-fold greater in anti-VEGF antibody-treated animals compared with vehicle-treated animals and, interestingly, no liver metastases were detected in cabozantinib-treated animals. In addition, improved overall survival was noted in the cabozantinib-treated animals. Median survival was 14.7 weeks for vehicle-treated animals $(\mathrm{n}=12)$ and 16.4 weeks for anti-VEGF antibody-treated animals $(\mathrm{n}=7 ; P<0.05$ versus vehicle). Animals treated with $M E T$ inhibitors demonstrated improved survival of $>20$ weeks.

\section{Cabozantinib activity in a preclinical bone metastasis model}

The MET and VEGF signaling pathways appear to play important roles in the function of osteoblasts and osteoclasts. The MET receptor for hepatocyte growth factor has been implicated as a mediator in many important aspects of tumor pathobiology, including tumor survival, growth, angiogenesis, invasion, and dissemination, and several MET tyrosine kinase 
receptors have been reported to show activity in cell lines and animal studies. ${ }^{18-21}$ MET expression has been observed by immunohistochemistry in both bone cell types in developing bone. ${ }^{10}$ Hepatocyte growth factor and MET are expressed by osteoblasts and osteoclasts in vitro and mediate cellular responses such as proliferation and migration. Osteoblasts and osteoclasts express VEGF and its receptors, and VEGF signaling in these cells is involved in potential autocrine and/ or paracrine feedback mechanisms regulating cell migration, differentiation, and survival. ${ }^{18}$ Secretion of hepatocyte growth factor by osteoblasts has been proposed as a key factor in osteoblast/osteoclast coupling and in the development of bone metastases by tumor cells that express $M E T .{ }^{19}$ Bone metastases in prostate cancer are more likely to express $M E T$ than other soft tissue metastases..$^{10}$ Preclinical studies in prostate cancer xenografts reported responses to cabozantinib therapy in nude mouse tibia (minimal bone lesions seen) as compared with development of multiple osteoblastic and osteolytic lesions in vehicle-treated controls. ${ }^{20}$ It is hypothesized that the osteoclast differentiation induced by cabozantinib may be responsible for the bone scan responses seen; however, the exact mechanism via which this occurs is unknown at present..$^{20}$ Treatment with cabozantinib appeared to decelerate both osteoblastic and osteolytic progression of prostate xenograft tumors in bone.

\section{Cabozantinib activity in prostate cancer}

A recently reported study ${ }^{22}$ evaluated the preclinical in vivo activity of cabozantinib in numerous prostate cancer cell lines, including Ace-1, C4-2B, and PC-3. In the tibial model of each of these cell lines, apoptosis of cancer cells in bone and improvement in bone mineral content were noted in the osteoblastic metastasis model (Ace-1) and in the mixed osteolytic and osteoblastic model (C4-2B). In the osteolytic model of PC-3 cells, no growth inhibition was noted in bone, but a response was noted in soft tissue metastases. Inhibition of angiogenesis was noted in subcutaneous PC-3 metastases but not in bone metastases. This suggests that close correlation of VEGF and MET inhibition is required for cabozantinib activity. In the androgen-responsive (LuCaP 35) model, administration of cabozantinib prevented or delayed tumor progression, as compared with in vehicle-treated control mice. The above observations would create a rationale for future evaluation of cabozantinib in earlier stages of prostate cancer, such as in the adjuvant setting for high-risk disease or hormone-sensitive disease.

VEGF inhibition, either by a single agent or coupled with chemotherapy, has not demonstrated clinical benefit in advanced prostate cancer. The presence of hypoxia results in increased generation of proangiogenic factors via activation of the met proto-oncogene and subsequent tumor growth and proliferation. ${ }^{23,24}$ This was demonstrated clinically in the randomized Phase III trials of docetaxel \pm bevacizumab ${ }^{25}$ and docetaxel \pm aflibercept,${ }^{26}$ with a lack of incremental benefit in comparison with docetaxel alone. It may be hypothesized that the critical role of $M E T$ in progression and proliferation of metastases is emphasized by the fact that dual Met and VEGF inhibition is essential to produce an anticancer effect in prostate cancer. Compounds that simultaneously inhibit VEGF and MET tyrosine kinase receptors are hence likely to be more effective anticancer agents than agents that target each of these receptors individually. ${ }^{27,28}$ In addition, cabozantinib has activity against other tyrosine kinase receptors that have been implicated in tumor pathobiology, including RET, KIT, FMS-like tyrosine kinase 3, and Tie-2.27

\section{Clinical activity of cabozantinib in prostate cancer}

Cabozantinib has demonstrated broad clinical activity in multiple tumor types, including medullary thyroid cancer, papillary thyroid cancer, breast, ovarian, prostate, and lung cancers, melanoma, glioblastoma, hepatocellular carcinoma, and renal cell carcinoma. ${ }^{6,26,27}$ Randomized registration trials in metastatic CRPC are currently ongoing (Figures 1 and 2). Promising responses have been noted in soft tissue tumor lesions and in visceral metastases, in addition to those seen in bone metastases (partial or complete resolution on bone scan). Reduction in markers of bone resorption and formation, reduction in circulating tumor cells (in subjects with prostate cancer), increased hemoglobin, improvement of bone pain, and less narcotic use in subjects with bone metastases are other indications of a response to cabozantinib.

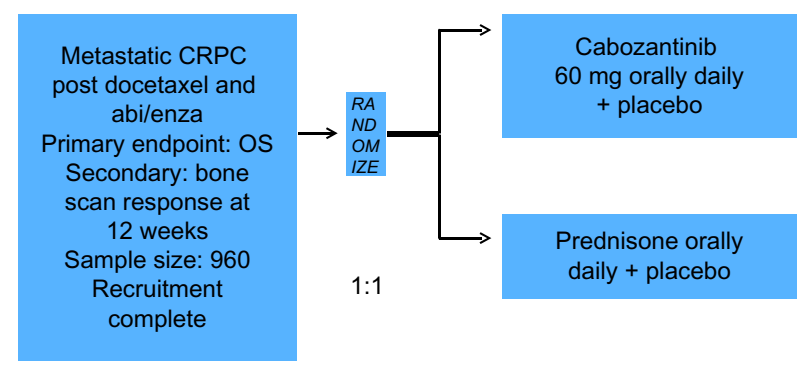

Figure I COMET-I[NCT0I605227]: Phase III double blind randomized trial of cabozantinib vs prednisone in metastatic CRPC post docetaxel and abiraterone/ enzalutamide.

Notes: Multicenter trial completed accrual, results awaited. Target sample size 960 patients.

Abbreviations: CRPC, castrate-resistant prostate cancer; OS, overall survival; abi, abiraterone; enza, enzalutamide. 


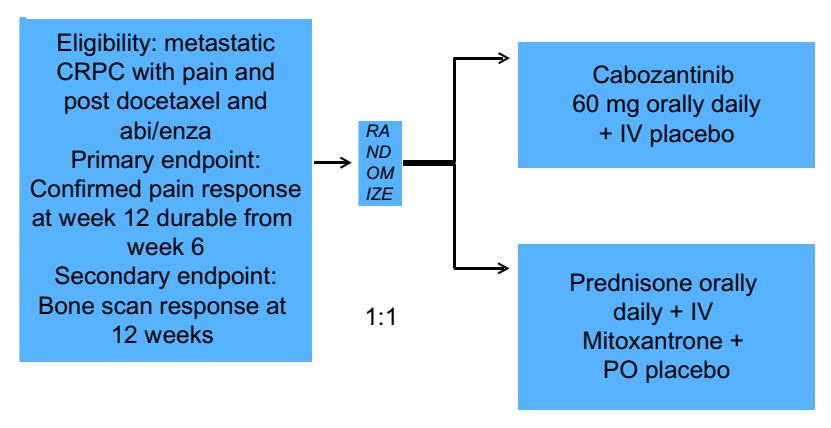

Figure 2 COMET-2(NCT0I522443): Phase III placebo controlled double blind randomized trial of cabozantinib vs mitoxantrone + prednisone in metastatic CRPC patients with pain, post docetaxel and abiraterone/enzalutamide.

Notes: Multicenter trial. Target accrual: 246, recruitment ongoing 100 patients.

Abbreviations: CRPC, castrate-resistant prostate cancer; IV, intravenous; PO, per os (by mouth); vs, versus.

Clinical efficacy has been demonstrated to date in medullary thyroid cancer. In a randomized, placebo-controlled study ${ }^{8}$ of 330 subjects with medullary thyroid cancer, a significant increase in median progression-free survival was demonstrated in the cabozantinib arm compared with the placebo arm (11.2 months versus 4.0 months, respectively; hazard ratio $0.28,95$ confidence interval $0.19-0.40$ ). Twenty-eight percent of cabozantinib-treated subjects demonstrated objective partial responses as compared with none in the placebo arm. Responses were durable, with a median response duration of 14.6 months. The only clinical trial completed in prostate cancer to date is a randomized Phase II discontinuation study. However, the results broadly revealed clinical activity in men with CRPC. An increase in median progression-free survival was observed in the cabozantinib arm compared with the placebo arm (23.9 weeks versus 5.9 weeks, respectively). ${ }^{6}$ The objective response rate at 12 weeks was only $5 \%$ and the stable disease rate was $75 \%$ (Table 1). In addition, effects on bone scan were assessed by an independent reader, and pain and narcotic use were prospectively assessed using an interactive voice recording system and a diary. Figure 3 shows examples of the different bone scan effects seen with cabozantinib therapy in CRPC bone metastases. Sixty-seven percent of subjects achieved a bone scan response, of which 4 subjects demonstrated a complete response. A bone scan response was noted even in the absence of a prostate-specific antigen (PSA) response, with discordance noted between PSA and bone scan responses in about $54 \%$ of patients. Among subjects with baseline pain of at least 4 on a $0-10$ scale, $64 \%$ had a minimum $30 \%$ decrease in average daily worst pain as compared with baseline. A third of the subjects were able to discontinue use of narcotic pain medication. As expected in a typical metastatic CRPC population, the majority of patients in the trial had bone metastases. These patients showed a marked reduction in total alkaline phosphatase from the elevated levels seen at baseline. This effect continued during the nonrandomized expansion phase of the study, and the majority of CRPC subjects on the assigned dose of 100 mg showed a reduction in circulating bone-specific alkaline phosphatase. These effects were independent of prior or concomitant treatment with bisphosphonates. Reductions in bone biomarkers were also evident in the $40 \mathrm{mg}$ dose cohort. Subjects achieved a bone scan response in both the $100 \mathrm{mg}$ and $40 \mathrm{mg}$ assigned nonrandomized expansion dose cohorts (67\% and $49 \%$, respectively). Sixty-four percent of subjects treated with the $100 \mathrm{mg}$ daily dose and $69 \%$ of those treated with the $40 \mathrm{mg}$ daily dose had a decrease of at least $30 \%$ in average daily worst pain score compared with baseline. In addition, more than half of the subjects decreased their use of narcotic pain medication.

\section{Pharmacokinetics, dose selection, and toxicities}

Cabozantinib is administered as a daily oral dose and has a half-life of about $91.3 \pm 33.3$ hours. Steady-state plasma
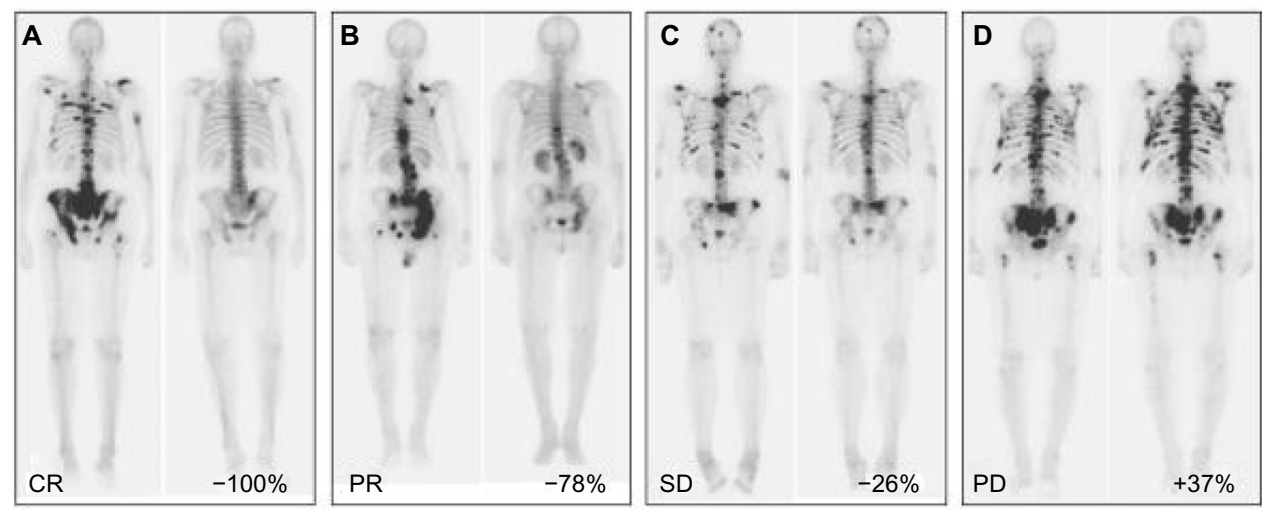

Figure 3 Cabozantinib effects on prostate cancer bone metastases. (A) Complete response: complete resolution of bone scan abnormalities; (B) partial response: $\geq 30 \%$ decrease in total bone scan lesion area (BSLA); (C) stable disease: $<30 \%$ increase or decrease in BSLA; (D) progressive disease: $>30 \%$ increase in BSLA. Abbreviations: SD, stable disease; CR, complete response; PR, partial response; PD, progressive disease. 
concentrations are reached within 15 days, ${ }^{29}$ and are about 4-5-fold higher at this time than plasma levels on day 1. The dose-escalation trial ${ }^{29}$ identified the Phase II dose to be $175 \mathrm{mg}$ daily; however, the increased incidence of toxicities ( $90 \%$ of patients in the Phase I trial had at least one adverse event) warranted dose reduction in the Phase II and III trials. The dose used in the medullary thyroid cancer clinical trial was $140 \mathrm{mg}$ daily, and a number of toxicities were found to be dose-dependent. In the initial randomized discontinuation trial, the frequency of drug discontinuation due to toxicities was $16 \%$. In a subsequent study in advanced prostate cancer, dose de-escalation was done with continued assessment of efficacy to determine the optimal dose for CRPC trials. ${ }^{30}$ Dose levels of $60 \mathrm{mg}$ and $40 \mathrm{mg}$ were found to have equivalent efficacy and remarkably lower toxicity, thereby justifying the choice of a lower starting dose of $60 \mathrm{mg}$ daily in the ongoing Phase III prostate cancer trials. ${ }^{30}$

\section{Discussion}

The response rate and progression-free survival on cabozantinib in the Phase I/II untreated or pretreated CRPC patient populations are comparable with other therapies that have already established overall survival benefit in advanced CRPC. These include therapies such as sipuleucel T, abiraterone, cabazitaxel, enzalutamide, and alpharadin/RAD-223. Cabozantinib demonstrated palliative efficacy against bone lesions, and the potential to alleviate the morbidities of bone metastases, such as pain and other skeletal-related events. Biomarkers that would help guide selection of therapy are not available at present. The decreases in pain, t-alkaline phosphatase, PSA, bone-specific alkaline phosphatase, and circulating tumor cell levels can be used collectively for assessment of response. The governing indicator of response remains patient-reported pain scores and symptom relief achieved. However, in the current environment of prostate cancer therapeutics, a palliative benefit or a time to progression advantage will not be adequate to justify clinical use of an agent. An overall survival benefit would be required. Crossover of placebo-treated patients to other effective regimens could make achievement of that target challenging. Eligibility for the randomized, placebo-controlled trial ${ }^{31}$ requires patients to have disease progression following at least docetaxel and either abiraterone or enzalutamide. If cabozantinib does not demonstrate an overall survival benefit in this pretreated patient population, justification of additional studies in earlier stages of prostate cancer will be very difficult.

Cabozantinib is well tolerated and has the potential to demonstrate antitumor responses even in heavily pretreated advanced prostate cancer. Remarkable responses in bone metastases as well as in measurable disease have been reported to date. ${ }^{6,30}$ Clinicians using this agent will face the dilemma of response assessment. PSA changes are discordant with benefit and progression-free survival at least $50 \%$ of the time, and the changes seen on bone scans have not been validated as determinants of response. It has not been clear whether the bone scan changes seen are related to bone modulation alone or indicate a specific anticancer effect on metastases. Pain assessment is a very cumbersome and subjective endpoint to characterize. Bone markers such as total and bone-specific alkaline phosphatase may need to be used as surrogates for response to cabozantinib; however, these are nonspecific and could be affected by other bone-targeted therapies such as zoledronate or denosumab. Preclinical and metastatic tissue imaging and biopsy studies are in progress at our institution (Karmanos Cancer Institute) and will enhance our understanding of the mechanism of response to this intriguing agent. ${ }^{32}$ In addition, the above-mentioned study may help to establish better surrogates of response that can guide duration and extent of therapy.

Cabozantinib has a rational clinical development plan starting with the indication in an orphan status disease, ie, medullary thyroid cancer. After preliminary evidence of anticancer effects in advanced prostate cancer, a randomized clinical trial ${ }^{31}$ has completed accrual in patients with metastatic CRPC pretreated with docetaxel, and abiraterone or enzalutamide. The future of cabozantinib in prostate cancer hinges on the overall survival results of this registration trial. Combination studies with agents such as abiraterone, enzalutamide, and docetaxel can be considered in the future. Studies of cabozantinib are also ongoing in other disease entities with limited therapeutic options, such as hepatocellular and non-small cell lung cancer.

\section{Conclusion}

Cabozantinib is a promising agent that could be incorporated into the therapeutic armamentarium for advanced prostate cancer. The registration clinical trial ${ }^{31}$ is evaluating the overall survival benefit in metastatic CRPC with progression after docetaxel, abiraterone, and/or enzalutamide. Cabozantinibbased combination therapies are likely to be evaluated in the future. A better understanding of the mechanism of action could help in the development of biomarkers that would enable patient selection and response assessments when using this dual MET and VEGF inhibitor. 


\section{Disclosure}

The author is the Principal Investigator of a study that has received drug only support from Exelexis Inc. The author reports no other conflicts in this work.

\section{References}

1. Kantoff PW, Higano CS, Shore ND, et al. Sipuleucel-T immunotherapy for castration-resistant prostate cancer. N Engl J Med. 2010;363(5): 411-422.

2. De Bono JS, Logothetis CJ, Molina A, et al. Abiraterone and increased survival in metastatic prostate cancer. $N$ Engl J Med. 2011;364(21): 1995-2005.

3. De Bono JS, Oudard S, Ozguroglu M, et al. Prednisone plus cabazitaxel or mitoxantrone for metastatic castration-resistant prostate cancer progressing after docetaxel treatment: a randomised open-label trial. Lancet. 2010;376(9747):1147-1154.

4. Scher HI, Fizazi K, Saad F, et al. Increased survival with enzalutamide in prostate cancer after chemotherapy. N Engl J Med. 2012;367(13): 1187-1197.

5. Parker C, Nilsson S, Heinrich D, et al. Alpha emitter radium-223 and survival in metastatic prostate cancer. N Engl J Med. 2013;369(3): 213-223.

6. Smith DC, Smith MR, Sweeney C, et al. Cabozantinib in patients with advanced prostate cancer: results of a Phase II randomized discontinuation trial. $J$ Clin Oncol. 2013;31(4):412-419.

7. Yakes FM, Chen J, Tan J, et al. Cabozantinib (XL184), a novel MET and VEGFR2 inhibitor, simultaneously suppresses metastasis, angiogenesis, and tumor growth. Mol Cancer Ther. 2011;10(12):2298-2308.

8. Elisei R, Schlumberger MJ, Müller SP, et al. Cabozantinib in progressive medullary thyroid cancer. J Clin Oncol. 2013;31(29):3639-3646.

9. Humphrey PA, Zu X, Zarnegar R, et al. Hepatocyte growth factor and HS receptor (c-Met) in prostatic carcinoma. Am J Pathol. 1995;147(2): 386-396.

10. Knudsen BS, Gmyrek GA, Inra J, et al. High expression of the Met receptor in prostate cancer metastasis to bone. Urology. 2002;60(6): 1113-1117.

11. Pàez-Ribes M, Allen E, Hudock J, et al. Antiangiogenic therapy elicits malignant progression of tumors to increased local invasion and distant metastasis. Cancer Cell. 2009;15(3):220-231.

12. Schmidt L, Duh FM, Chen F, et al. Germline and somatic mutations in the tyrosine kinase domain of the MET proto-oncogene in papillary renal carcinomas. Nat Genet. 1997;16(1):68-73.

13. Sennino B, Ishiguro-Oonuma T, Wei Y, et al. Suppression of tumor invasion and metastasis by concurrent inhibition of c-Met and VEGF signaling in pancreatic neuroendocrine tumors. Cancer Discov. 2012;2(3):270-287.

14. You WK, Sennino B, Williamson CW, et al. VEGF and c-Met blockade amplify angiogenesis inhibition in pancreatic islet cancer. Cancer Res. 2011;71(14):4758-4768.

15. Aftab DT, McDonald DM. MET and VEGF: synergistic targets in castration-resistant prostate cancer. Clin Transl Oncol. 2011;13(10): 703-709.

16. Sennino B, Naylor RM, Tabruyn SB, You WK, Aftab DT, McDonald DM. Reduction of tumor invasiveness and metastasis and prolongation of survival of RIP-Tag2 mice after inhibition of VEGFR plus c-Met by XL184. Mol Cancer Ther. 2009;8(Suppl 12):A13.

\section{Core Evidence}

\section{Publish your work in this journal}

Core Evidence is an international, peer-reviewed open-access journal evaluating the evidence underlying the potential place in therapy of drugs throughout their development lifecycle from preclinical to postlaunch. The focus of each review is to evaluate the case for a new drug or class in outcome terms in specific indications and patient groups.

Submit your manuscript here: http://www.dovepress.com/core-evidence-journal
17. Sennino B, Ishiguro-Oonuma T, Schriver BJ, et al. Inhibition of c-Met reduces lymphatic metastasis in RIP-Tag2 transgenic mice. Cancer Res. 2013;73(12):3692-3703.

18. Street J, Lenehan B. Vascular endothelial growth factor regulates osteoblast survival: evidence for an autocrine feedback mechanism. J Orthop Surg Res. 2009;4:19-23.

19. Grano M, Galimi F, Zambonin G, et al. Hepatocyte growth factor is a coupling factor for osteoclasts and osteoblasts in vitro. Proc Natl Acad Sci U SA. 1996;93(15):7644-7648.

20. Schimmoller F, Zayzafoon M, Chung LWK, et al. Cabozantinib (XL184), a dual MET-VEGFR2 inhibitor, blocks osteoblastic and osteolytic progression of human prostate cancer xenografts in mouse bone. Mol Cancer Ther. 2011;10(11 Suppl 1):233.

21. Ono K, Kamiya S, Akatsu T, et al. Involvement of hepatocyte growth factor in the development of bone metastasis of a mouse mammary cancer cell line, BALB/c-MC. Bone. 2006;39(1):27-34.

22. Dai J, Zhang H, Karatsinides A, et al. Cabozantinib inhibits prostate cancer growth and inhibits tumor induced bone lesions. Clin Cancer Res. 2014;20(3):617-630.

23. Pennacchietti S, Michieli P, Galluzzo M, et al. Hypoxia promotes invasive growth by transcriptional activation of the met protooncogene. Cancer Cell. 2003;3(4):347-361.

24. Fernando NT, Koch M, Rothrock C, et al. Tumor escape from endogenous, extracellular matrix-associated angiogenesis inhibitors by up-regulation of multiple proangiogenic factors. Clin Cancer Res. 2008;14(5):1529-1539.

25. Kelly WK, Halabi S, Carducci M, et al. Randomized, double-blind, placebo-controlled Phase III trial comparing docetaxel and prednisone with or without bevacizumab in men with metastatic castrationresistant prostate cancer: CALGB 90401. J Clin Oncol. 2012;30(13): $1534-1540$.

26. Tannock I, Fizazi K, Sergei I, et al. Aflibercept versus placebo in combination with docetaxel and prednisone for treatment of men with metastatic castration-resistant prostate cancer (VENICE): a Phase 3, double-blind randomised trial. Lancet Oncol. 2013;14(8):760-768.

27. Eder JP, Vande Woude GF, Boerner SA, LoRusso PM. Novel therapeutic inhibitors of the c-Met signaling pathway in cancer. Clin Cancer Res. 2009;15(7):2207-2214.

28. Vankayala H, Lorusso P, Vaishampayan UN. C-MET as a novel target for the treatment of renal cell carcinoma. In: Figlin RA, Rathmell WK, Rini BI, editors. Renal Cell Carcinoma. New York, NY, USA: Springer; 2012.

29. Kurzrock R, Sherman SI, Ball DW, et al. Activity of XL184 (cabozantinib), an oral tyrosine kinase inhibitor, in patients with medullary thyroid cancer. J Clin Oncol. 2011;29(19):2660-2666.

30. Lee RJ, Saylor PJ, Michaelson MD, et al. A dose-ranging study of cabozantinib in men with castration-resistant prostate cancer and bone metastases. Clin Cancer Res. 2013;19(11):3088-3094.

31. Exelixis. Study of Cabozantinib (XL184) Versus Prednisone in Men With Metastatic Castration-resistant Prostate Cancer Previously Treated With Docetaxel and Abiraterone or MDV3100 (COMET-1). Available from: http://clinicaltrials.gov/show/NCT01605227. NLM identifier: NCT01605227. Accessed March 25, 2014.

32. Barbara Ann Karmanos Cancer Institute. Cabozantinib-S-Malate in Treating Patients With Hormone-Resistant Metastatic Prostate Cancer. Available from: http://clinicaltrials.gov/show/NCT01812668. NLM identifier: NCT01812668. Accessed March 25, 2014.

\section{Dovepress}

The manuscript management system is completely online and includes a very quick and fair peer-review system, which is all easy to use. Visit http://www.dovepress.com/testimonials.php to read real quotes from published authors. 